\title{
Evaluation of slab images in the northwestern Pacific
}

\author{
Fumiko Tajima ${ }^{1}$, Yoshio Fukao ${ }^{2}$, Masayuki Obayashi ${ }^{2}$, and Taro Sakurai ${ }^{2}$ \\ ${ }^{1}$ Physics Department, University of Texas at Austin, U.S.A. \\ ${ }^{2}$ Earthquake Research Institute, University of Tokyo, Japan \\ (Received July 21, 1998; Revised September 11, 1998; Accepted October 6, 1998)
}

\begin{abstract}
Recent P wave travel-time tomographic studies using data from the International Seismological Centre (ISC) catalog determine a large-scale subhorizontal high velocity anomaly in the northwestern Pacific subduction zones and it has been interpreted as imaging stagnant slab in the upper mantle transition zone ( $\sim 400$ to $700 \mathrm{~km})$. The limited resolution of the travel time tomographic studies in this depth range, however, makes it difficult to evaluate accurately the vertical and lateral extent of a stagnant slab. A broadband waveform modeling of triplicated regional seismic waves which are very sensitive to the transition zone structure is useful to evaluate the velocity structure along the propagation paths and therefore to constrain the spatial distribution of anomalies. This study thus compares tomographic images from the model of Obayashi et al. (1997) with results of the regional waveform modeling by Tajima and Grand (1998). The ISC tomographic model shows the largest lateral extent of high velocity anomaly in the layer of 478 to $551 \mathrm{~km}$ depths although part of this spread is likely due to the deteriorated resolution in that depth range. The waveform modeling suggests that the strong high velocity anomaly associated with a stagnant slab exists below $525 \mathrm{~km}$ with its maximum intensity in the top $50 \mathrm{~km}$ and decreases with increasing depth to vanish at $660 \mathrm{~km}$. These results along with a recent global SH velocity model SAW12D of Li and Romanowicz (1996) which has the strongest high velocity anomaly in a depth range 500-550 km may be integrated into an image of a stagnant slab. The anomalous velocity structure associated with a stagnant slab has its maximum intensity not immediately above the $660 \mathrm{~km}$ discontinuity but in a depth range $\sim 100 \mathrm{~km}$ above it. This feature appears to be consistent with a thermochemical model of down-going slab in which a larger velocity contrast with the surrounding mantle is expected at a shallower depth of the transition zone. The ISC tomographic model and waveform modeling consistently show that the deflected slabs are not laterally continuous but are separated into a few subregions. Beneath the northeastern China where the resolution is good, the slab related anomaly above the $660 \mathrm{~km}$ discontinuity is accompanied by its downward extension into the lower mantle.
\end{abstract}

\section{Introduction}

The fate of subducting slabs at the bottom of the upper mantle has been debated over a decade (e.g., Creager and Jordan, 1984, 1986; Zhou and Clayton, 1990). Recently published three dimensional (3-D) tomographic models using $\mathrm{P}$ wave travel times from the International Seismological Centre (ISC) bulletin provide large-scale images of varying high velocity anomalies associated with subduction zones in the western Pacific (van der Hilst et al., 1991, 1997; Fukao et al., 1992; Widiyantoro and van der Hilst, 1996).

The anomalous features commonly determined in the models are a large subhorizontal high velocity anomaly above and/or across the " 660 " km discontinuity in the northwestern Pacific and a high velocity zone which crosses the $660 \mathrm{~km}$ discontinuity and then dips to a shallower dip in the Java subduction zone. The subhorizontal anomalies may indicate that a large volume of subducted slab is stagnant above the $660 \mathrm{~km}$ discontinuity in the back arc of the southern Kuriles, Japan, Izu-Bonin and Ryukyu subduction zones. In contrast the slab in Java appears to directly penetrate the $660 \mathrm{~km}$ discontinuity and then be trapped in the uppermost part of the lower mantle. In either case the subducted slabs tend to be trapped in the

Copy right (c) The Society of Geomagnetism and Earth, Planetary and Space Sciences (SGEPSS); The Seismological Society of Japan; The Volcanological Society of Japan; The Geodetic Society of Japan; The Japanese Society for Planetary Sciences.
Bullen's transition region (C layer: $\sim 400$ to $1000 \mathrm{~km}$; see Bullen (1963)) whose geophysical significance has recently been revisited by Kawakatsu and Niu (1994). Such tendency of a subducted slab is seen not only in the western Pacific but also in other subduction zones (van der Hilst et al., 1997) although the details are different from region to region. Such apparent similarity and difference of slab behaviors revealed by the tomographic models stimulated debates in relation to mantle convection patterns. There are concerns, however, about the resolution of ISC $\mathrm{P}$ wave travel-time data for the transition zone depths ( $\sim 410$ to $660 \mathrm{~km})$ as the depth range is poorly sampled by first arriving rays.

On the other hand triplicated seismic waves at regional distances are very sensitive to transition zone structure as they turn in and therefore sample the depth range strongly. Thus Tajima and Grand $(1995,1998)$ carried out a regional broadband waveform modeling which supplements the resolution of large scale 3-D tomographic inversion. The present study attempts to evaluate the tomographic model of Obayashi et al. (1997) by comparing the tomographic images with results of the regional waveform modeling of Tajima and Grand (1998). Here we would like to make a note that computing synthetics using the large-scale tomographic model would produce only very long-period waveforms which are not sensitive to the transition zone structure, and therefore it is not reasonable to compare the synthetics between these two approaches. Re- 
Fukao et al. (1992)

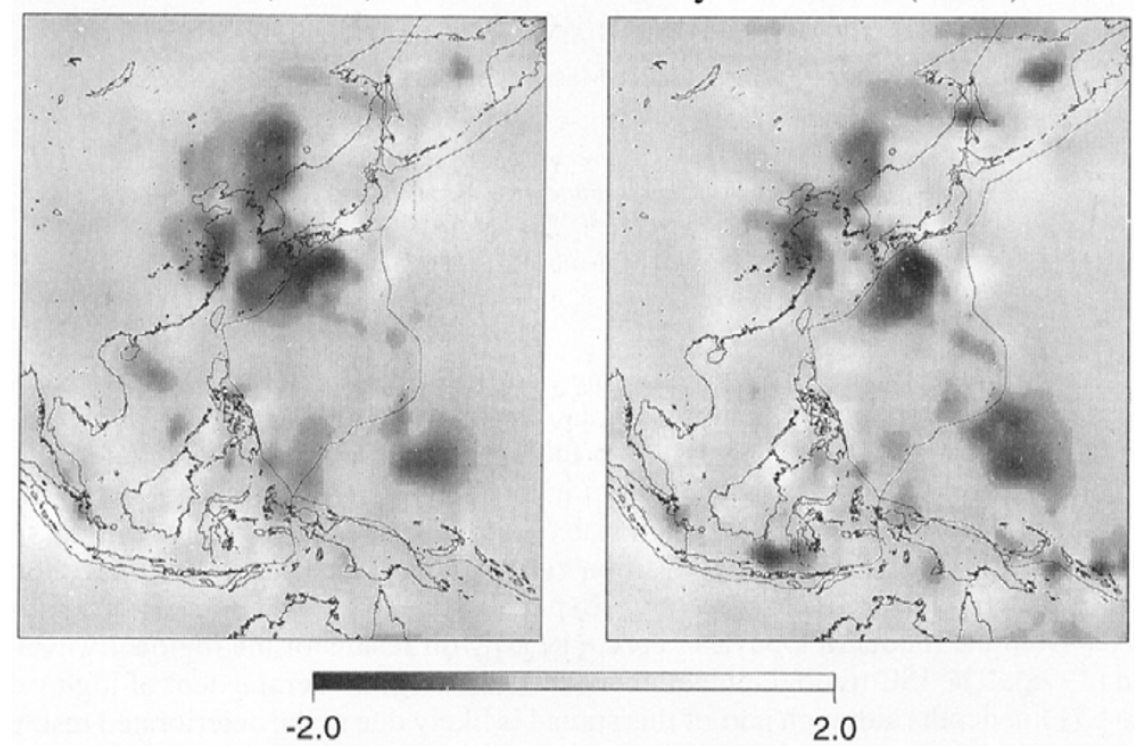

Fig. 1. Comparison of the slowness perturbation $(-2$ to $+2 \%)$ patterns between the ISC P wave tomographic model G2 (Fukao et al., 1992) and its improved version G3 (Obayashi et al., 1997) in the depth range 628-712 km that includes the upper and lower mantle boundary.

solving kernels are also computed to evaluate the resolution of the tomographic images for the regions where structural changes of high velocity anomalies are identified.

\section{ISC Tomographic Model: Improved Images of Slabs}

The advantage of ISC P travel-time tomographic inversion is to obtain a large-scale image of velocity anomalies of the Earth's interior. Fukao and his co-workers have developed the method of 3-D tomographic inversion with ISC P travel time data and produced several models of mantle structure systematically (Inoue et al., 1990; Fukao et al., 1992; Sakurai et al., 1995; Obayashi et al., 1997).

Inoue et al. (1990) presented the method of inversion and their first generation model of 3-D global tomographic inversion of the whole mantle (hereafter Model G1). Model G1 was derived using the spherically symmetric Earth model by Herrin et al. (1968) as the initial model. In the inversion the entire mantle was discretized into 32,768 blocks, i.e., the horizontal cell size was $5.625^{\circ} \times 5.625^{\circ}$ both in latitude and longitude and the layer thickness was varied from $29 \mathrm{~km}$ just below the surface to $334 \mathrm{~km}$ just above the core-mantle boundary (CMB). The data set consisted of $\mathrm{P}$ wave traveltimes from events which are listed in the ISC bulletin with a body wave magnitude $m_{b}$ of 4 or greater and 20 or more station readings during the period from 1964 to 1985 . The detail of the method can be checked in Inoue et al. (1990). Model G1 is one of the first models which attempted to delineate relatively short wavelength structure of the whole mantle and identified slab-like high velocity zones beneath the Western Pacific. However, slab related structure was poorly resolved due to the discretization size of blocks.
Fukao et al. (1992) subdivided the blocks into finer ones (1/4 of the original block size both in latitude and longitude and $1 / 2$ of the depth) in the vicinity of the Western Pacific subduction zones and attempted to obtain a better resolution of images for the high velocity zones. With the revised discretization the total number of blocks was 55,735 , about 1.7 times as large as in Model G1. About 410,000 first arriving $\mathrm{P}$ travel time data were chosen from the ISC bulletin for events with an $m_{b}$ of 4 or greater for the period from 1976 to 1985 . The initial model is a spherically averaged one of Model G1 which does not have discontinuities in the transition zone. During the investigation an alternative reference model with second-order discontinuities at around 400 and $670 \mathrm{~km}$ depths was tested but did not show any significant difference in the inversion result because of the poor sampling of turning rays in this depth range.

The 3-D model produced by Fukao et al. (1992) (hereafter Model G2) shows a large scale varying seismic image associated with subduction zones in the western Pacific. The high velocity zone beneath the southern Kuriles to Izu-Bonin arcs bends to subhorizontal near the leading edge of the WadatiBenioff zone and extends toward the Eurasian continent over a distance of more than $1000 \mathrm{~km}$. This anomalous feature appears to indicate a large volume of subducted slab is stagnant in the transition zone. It is also noted that part of the subhorizontal high velocity zone is accompanied by a blob which reaches to a depth of about $800 \mathrm{~km}$. On the other hand the slab image in the Java arc penetrates the transition zone into lower mantle and then bends to a shallow dip with a considerable spread up to a depth of about $1200 \mathrm{~km}$. Gross features of Model G2 are similar to those obtained by van der Hilst et al. (1991) and Widiyantoro and van der Hilst (1996) 
410 - $478 \mathrm{~km}$

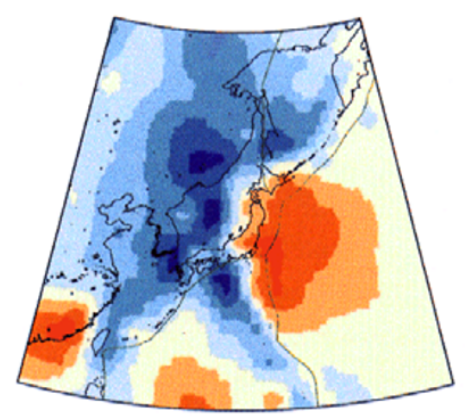

$629-712 \mathrm{~km}$

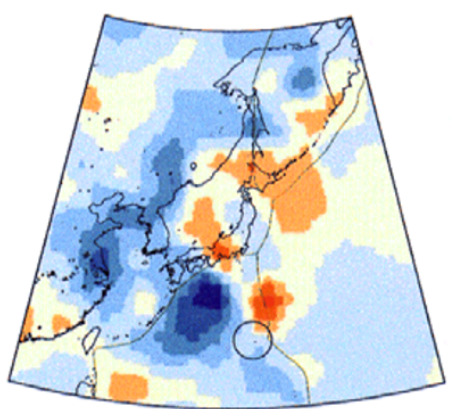

fast $2.0 \%$
$478-551 \mathrm{~km}$

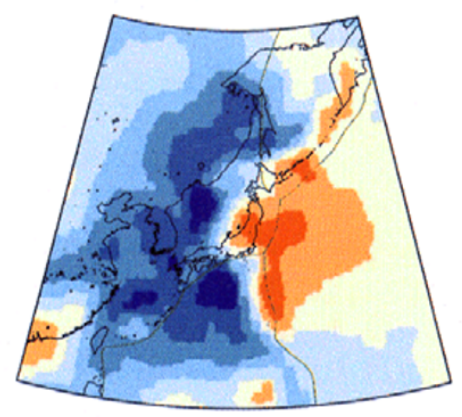

$712-800 \mathrm{~km}$
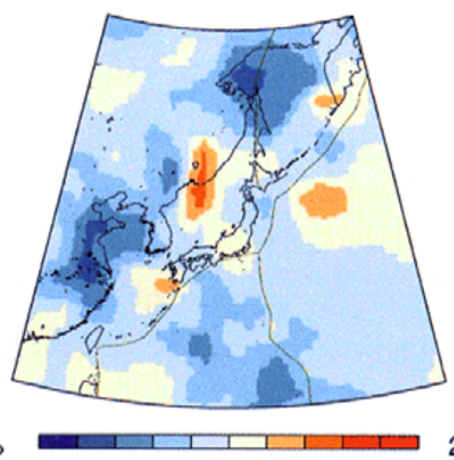

(a)
$551-629 \mathrm{~km}$

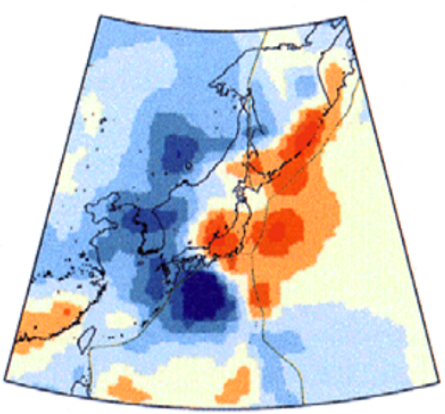

800 - $893 \mathrm{~km}$

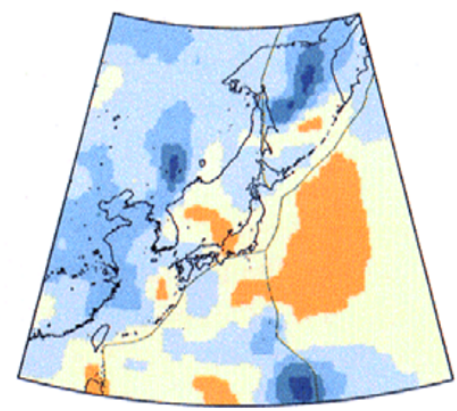

$2.0 \%$ slow
$445 \mathrm{~km}$

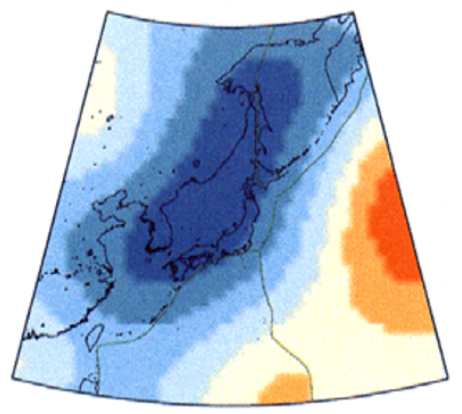

$670 \mathrm{~km}$

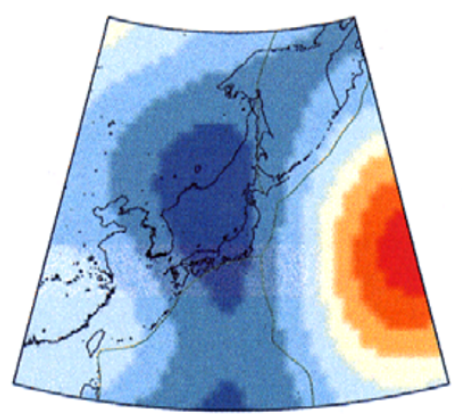

$515 \mathrm{~km}$

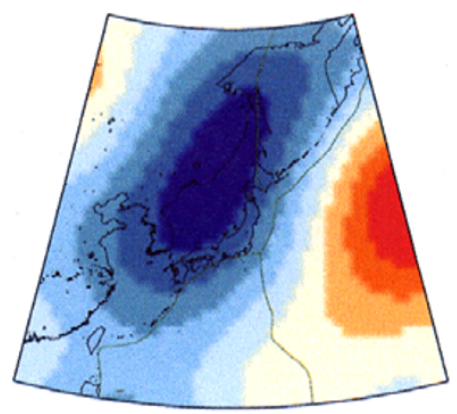

$755 \mathrm{~km}$

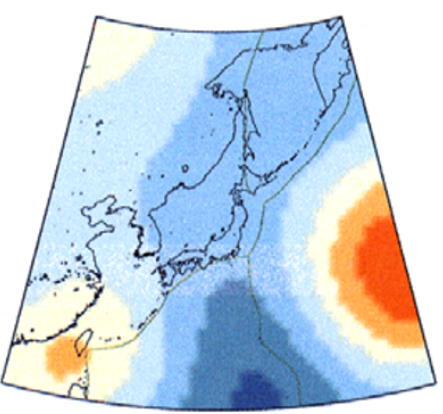

$590 \mathrm{~km}$

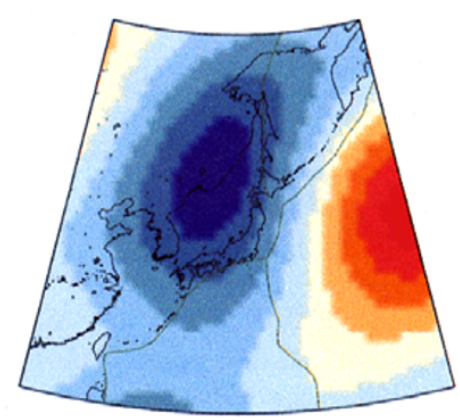

$845 \mathrm{~km}$

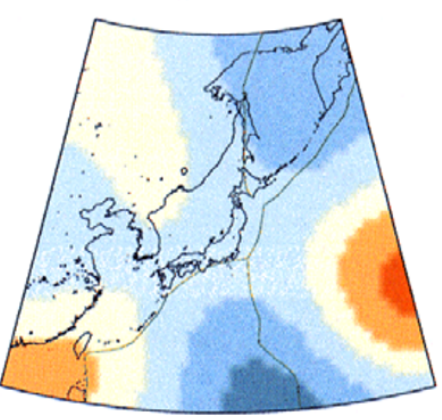

fast $2.0 \%$

$2.0 \%$ slow

(b)

Fig. 2. Comparison of the slowness perturbation $(-2$ to $+2 \%)$ patterns for the depth range in the transition zone under the northwestern Pacific. (a) ISC P-wave tomographic model G3 by Obayashi et al. (1997) in which the blockwise variation of velocity anomaly is slightly smoothed. The open circle on the map indicates an approximate bottoming location of the seismic rays from Events \#8 and \#11 to GUMO (see Fig. 4). (b) S velocity model SAW12D from the waveform inversion by Li and Romanowicz (1996). 
in the western Pacific subduction zones. There are some notable discrepancies between these tomographic models and previously published studies which suggest slab penetration in the northwestern Pacific (Creager and Jordan, 1984, 1986; Kamiya et al., 1988, 1989). Fukao et al. (1992) addressed that a high velocity anomaly blob may sink into the lower mantle beyond the flattened slab which Kamiya et al. (1988, 1989) may have misinterpreted as the direct slab penetrating into lower mantle.

Recently Obayashi et al. (1997) produced another model (Model G3) using the same method as in Fukao et al. (1992) but with more data, about two millions of ISC P arrival times from 12,000 selected events that occurred with an $m_{b}$ of 5 or greater during the period from 1964 to 1991 and have 20 or more $\mathrm{P}$ arrival time readings (note $\mathrm{G} 3$ was refined from the model which Sakurai et al. (1995) presented). Events were selected so that the data distribution, and accordingly the sampling density is as uniform as possible. The data volume is five times as large as the one used for Model G2. Model G2 was used as the initial model. The increase of data reduced the variance of the inversion resulting in a sharper tomographic image than the previous models. A few different tests were performed to check the resolution of the tomographic model. A checker board test using the same discretization as in Model G3 shows that the resolution for the upper mantle is generally poor except near the Japan islands and eastern coast of the Eurasian continent (Fig. A1; see Appendix for some details).

Figure 1 shows a map view comparison between Models G2 and G3 which are presented in terms of velocity perturbation from their spherically averaged models for the depth range $629-712 \mathrm{~km}$. This depth range includes the upper and lower mantle boundary. The color scale of velocity perturbations spans from -2.0 to $+2.0 \%$. Blue (or red) indicates regions with $\mathrm{P}$ wave velocity faster (or slower) than the reference model. Although the signatures of Model G3 are basically very similar to those in Model G2, there are significant and important differences. In Model G3 the high velocity anomaly beneath the northernmost Philippine Sea, probably the flattened part of the slab associated with the IzuBonin subduction zone, is clearly separated from the high velocity anomaly beneath eastern China, which is presumably the remnant older slab of the Pacific plate subducted prior to its subduction from the Izu-Bonin Trench. These two anomalous regions were not separated well from each other in G2. The lateral extent of the high velocity anomaly west of Japan Sea and East China Sea has become narrower. The high velocity anomaly associated with the subduction of the Indo-Australian plate along the Lesser Sunda Trench is better recognized in G3 than in G2. These features are just a few examples derived from the improved model as the result of the increased data volume.

In Fig. 2(a) the P wave velocity model G3 is compared to (b) the S wave velocity model SAW12D of Li and Romanowicz (1996) for six depth ranges between 410 and $890 \mathrm{~km}$ in the northwestern Pacific. The dataset and methodology as well as the resolution are very different from each other. Nevertheless the very long-wavelength features of the two models are remarkably similar to each other. For example, the largest lateral extent of high velocity anomalies is found along the eastern border of Russia (the western margin of Japan Sea) in a depth range around $515 \mathrm{~km}$. As the depth increases, the central core of the high velocity anomaly shifts progressively to the south toward the northernmost Philippine Sea. The high velocity anomaly loses its intensity rapidly at depths greater than $750 \mathrm{~km}$. The S wave velocity model S12WM13 of Su et al. (1994) also shows some similar tendencies of high velocity anomalies to these models. The long-wavelength features of Model G3 are, thus, supported by the existing global models based on waveform data. However, the present paper aims at an independent check of its relatively short-wavelength features using the results of regional waveform modeling by Tajima and Grand $(1995,1998)$.

\section{Implication of Anomalies by Waveform Model- ing}

If the subhorizontal image of high velocity anomaly in the northwestern Pacific represents a stagnant cold slab in the transition zone, mineral physics predicts also a deeper discontinuity depth than $660 \mathrm{~km}$ there due to the negative Clapeyron slope (Ringwood and Irifune, 1988). Such changes in seismic structure in the transition zone should affect triplicated waveforms at regional distances, but the depth range near the discontinuity can be strongly sampled only by secondary arrivals. Tajima and Grand (1995) thus analyzed regional broadband $\mathrm{P}$ waveforms in the frequency

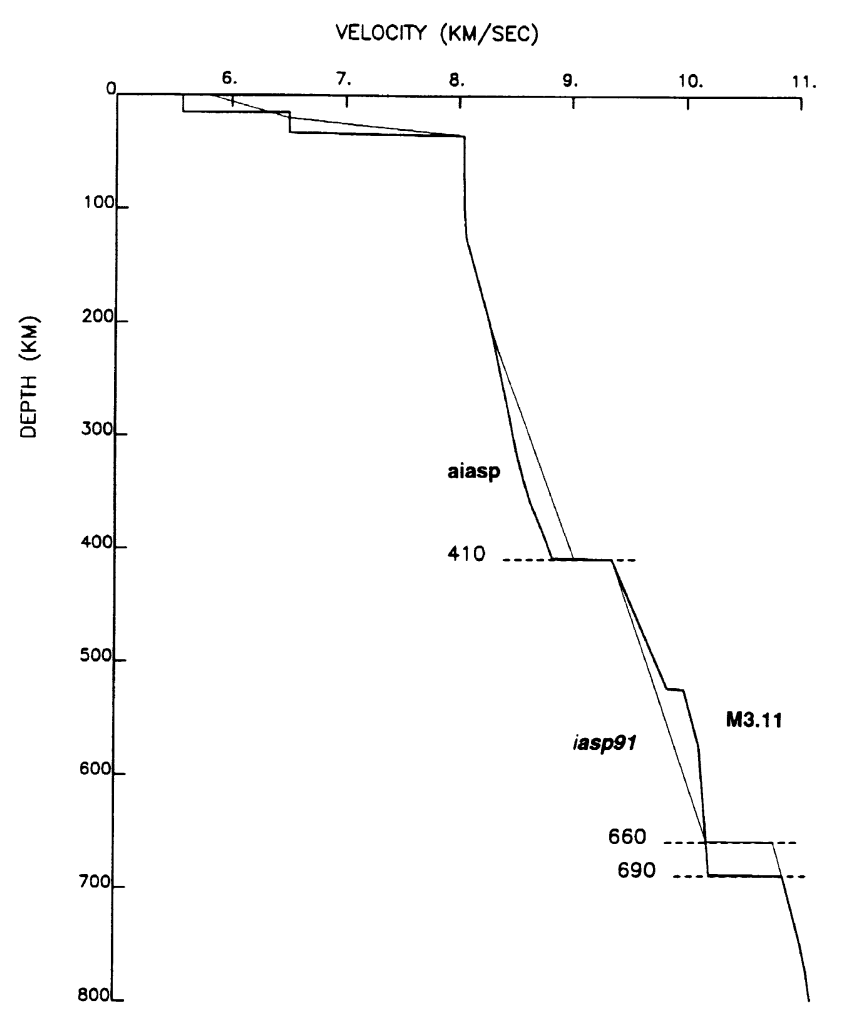

Fig. 3. P wave velocity model M3.11 derived by Tajima and Grand (1995, 1998). M3.11 shows anomalies in the depth range between 410 and $690 \mathrm{~km}$ (shown with a bold line) in comparison with a standard mode iasp91 (shown with a lighter line). For both of these models the structure in the depth range between 200 and $410 \mathrm{~km}$, and above $33 \mathrm{~km}$ was adopted from Fukao (1977) (indicated with aiasp), and that in the depth range between 33 and $200 \mathrm{~km}$ is the same as iasp 91 . 


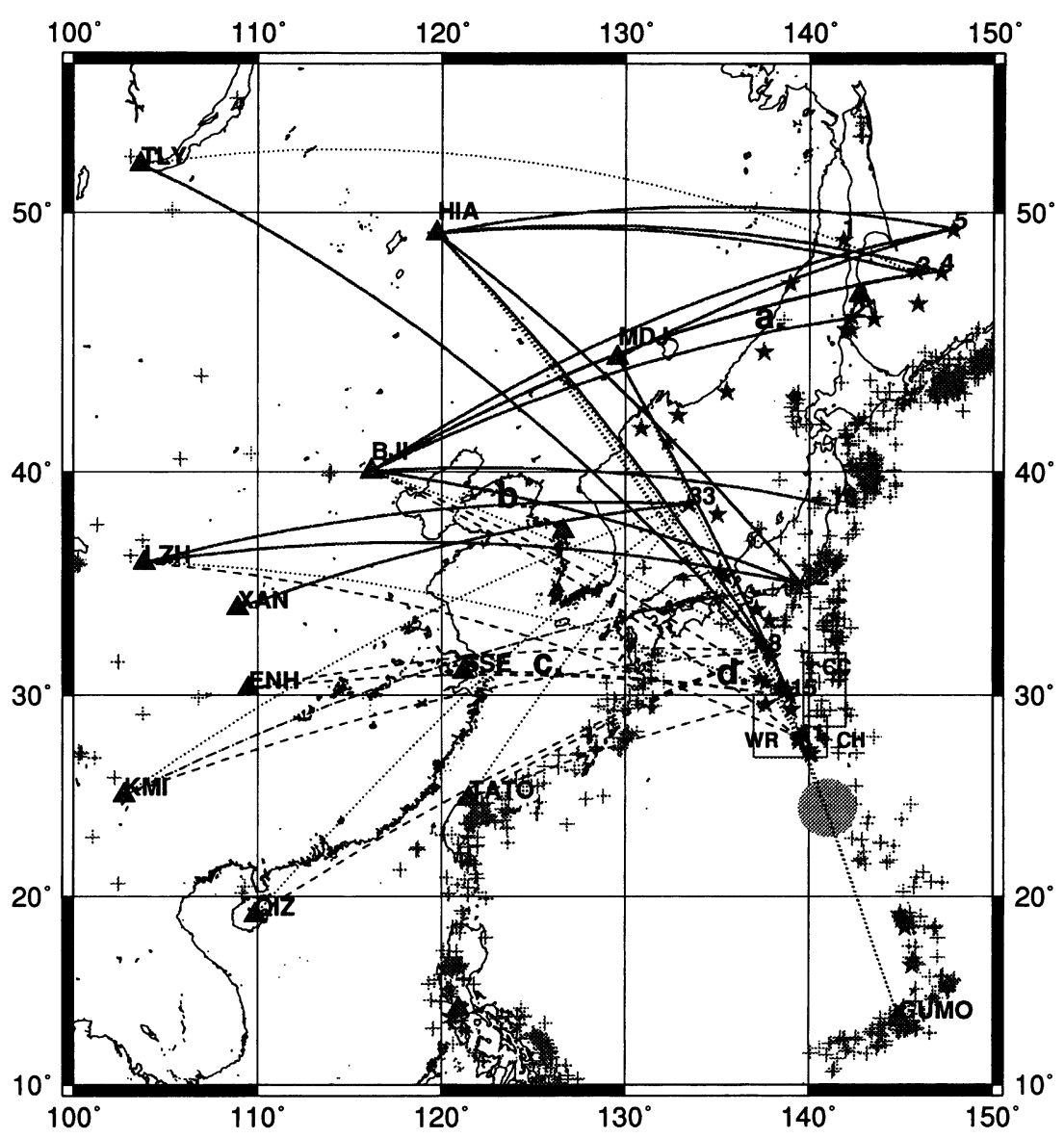

Fig. 4. Seismic rays which sample the northwestern Pacific subduction zones for selected events by Tajima and Grand (1998). Bold lines indicate rays along which $\mathrm{P}$ waves are modeled with M3.11 and thin dotted lines with iasp91. Dashed lines suggest a structure with high velocity anomaly in the deeper part of transition zone but not accompanied by a broad depression of the $660 \mathrm{~km}$ discontinuity.

band between $\sim 0.02$ and $1 \mathrm{~Hz}$ assuming a laterally homogeneous structure in the Fresnel zone along the ray path between the source and a receiver, and derived a 1-D velocity model M3.11 (indicated with a bold line in Fig. 3) for the northwestern Pacific region. Here a reflectivity synthetics method was used. Model M3.11 has a high velocity anomaly relative to iasp91 (thin line), a standard model (Kennett and Engdahl, 1991) in the transition zone where the anomaly is $1 \%$ immediately above and $2.5 \%$ immediately below the $525 \mathrm{~km}$ depth. The anomaly begins to decrease at $\sim 575 \mathrm{~km}$ and reduces to zero at $660 \mathrm{~km}$ depth. Unlike Model G3, the waveform modeling found no evidence of strong high velocity anomaly in the depth range shallower than $525 \mathrm{~km}$. The " 660 " $\mathrm{km}$ discontinuity depressed to $690 \mathrm{~km}$. The high velocity anomaly in this model should represent both of the inclined and subhorizontal parts of the subducted slab, or its seismically active and inactive parts. The depression of the " 660 " $\mathrm{km}$ discontinuity is consistent with the mineral physics prediction in a slab-dominated region as mentioned above.

Later Tajima and Grand (1998) analyzed more regional P waveforms which sampled the structure beneath a broader region in the northwestern Pacific by calculating synthetics with Model M3.11 and iasp91 and evaluated the lateral extent of transition zone anomalies. In the due course the velocity structure in the depth range between 200 and $410 \mathrm{~km}$ was modified to better fit the first arrival times using the Arctrench model of Fukao (1977) as denoted as aiasp in Fig. 3. Hereafter both Model M3.11 and iasp91 have this modification for the range above $410 \mathrm{~km}$. Their results show that the volume of transition zone high velocity anomalies is substantially smaller than the image in the ISC tomographic models. A brief summary is given below.

Figure 4 (modified from Tajima and Grand (1998)) shows seismic rays which sample the back arc regions of northwestern Pacific subduction zones. Bold lines indicate the rays along which the waveforms are modeled with M3.11 and thin dotted lines with iasp91. The numbers near epicenters are the event numbers (see Tajima and Grand (1998)).

Results of the corresponding waveforms are shown in Fig. 5 in which the observed waveforms are sorted into two groups, (a) ones which prefer M3.11 and (b) the others which prefer iasp91. For comparison synthetics calculated with the less preferred model, i.e., iasp91 in (a) or M3.11 in (b) are also shown. Model M3.11 explains P waves which sample the back arc region of the southern Kuriles to Japanese subduction zones (region a) and beneath and around the Bohai Sea (region b). We find a good correlation between the ray paths which prefer M3.11 and the fast regions in the tomographic map. This agreement supports the scenario that a flattened slab is stagnant near the bottom of the upper mantle. 


\section{M3.11 Preferred Waveforms}
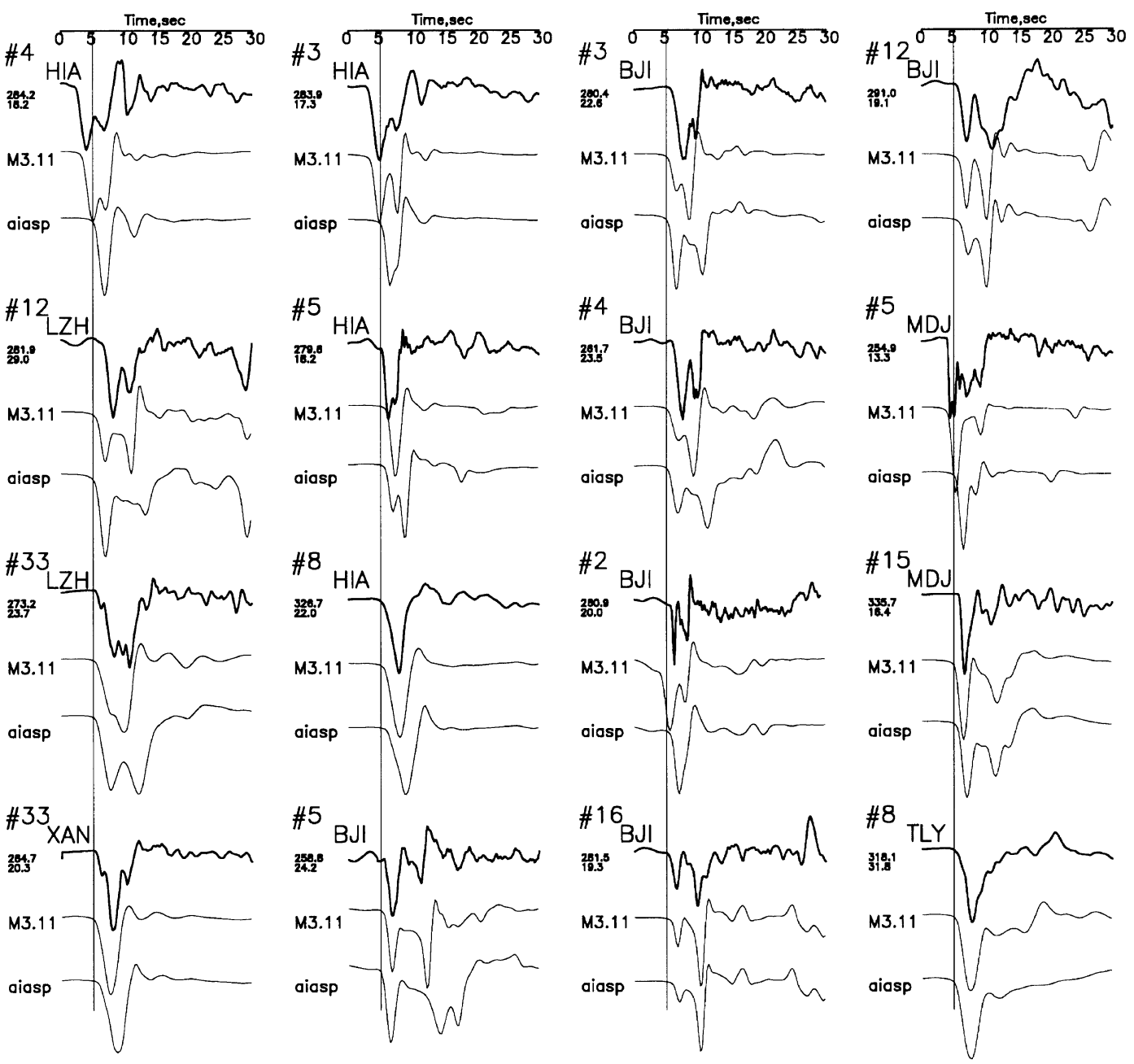

(a)

Fig. 5. Observed waveforms (top in each set) are compared with synthetics using (a) model M3.11 and (b) a standard model iasp91 with modification of aiasp (see the text). The calculated waveform with a preferred model is plotted in the middle and the other one at bottom.

The tomographic images shown in Fig. 2, however, suggest the largest lateral extent of high velocity anomaly at depths around 500-550 km while the strong velocity anomaly in M3.11 essentially starts at $525 \mathrm{~km}$ and gradually decreases with increasing depth.

There is a clear change of transition zone structure from M3.11 to iasp91 along the rays from events in the Izu-Bonin subduction zone to station HIA. No high velocity anomalies are found for the Yellow Sea to East China Sea region, the back arc of southwestern Japan to Ryukyu trench (region c). For many source-receiver geometries the observed waveforms are explained neither by M3.11 nor by iasp91. For waveforms which strongly sampled the structure beneath the northernmost Philippine Sea plate (region d) and propagated through beneath East China Sea an adequate velocity model seems to have high velocity anomaly in the transition zone like M3.11 but without being accompanied by a broad depression of the $660 \mathrm{~km}$ discontinuity (rays indicated with dashed lines in Fig. 4) although the detailed analysis has yet to be done (Tajima and Grand, 1998). The characteristics of the velocity structure in region $d$ are similar to those obtained by Brudzinski et al. (1997). The tomographic image shows an eminent zone of high velocity anomaly beneath the northernmost Philippine Sea in the depth range up to $712 \mathrm{~km}$, which sharply disappears below $712 \mathrm{~km}$ (Fig. 2(a)). This image may be a reflection of transition zone anomaly with the apparent absence of the depression of the $660 \mathrm{~km}$ discontinuity.

Figure 4 also shows the areas where the other investigators found points of depression of the " 660 " $\mathrm{km}$ discontinuity beneath the Izu-Bonin subduction zone (indicated with small boxes denoted as WR for Wicks and Richard (1993), CC for Castle and Creager (1997) and $\mathrm{CH}$ for Collier and Helffrich (1997)). The shaded circle indicates an approximate bottoming location of the seismic rays from Events \#8 and \#11 to GUMO which do not show transition zone anomaly. The bottoming location is also indicated by an open circle in the tomographic map (Fig. 2(a); see also Fig. 7 for the crosssection view of the ray path). This open circle is located further south of the high velocity region under the northern- 
iasp91 Preferred Waveforms
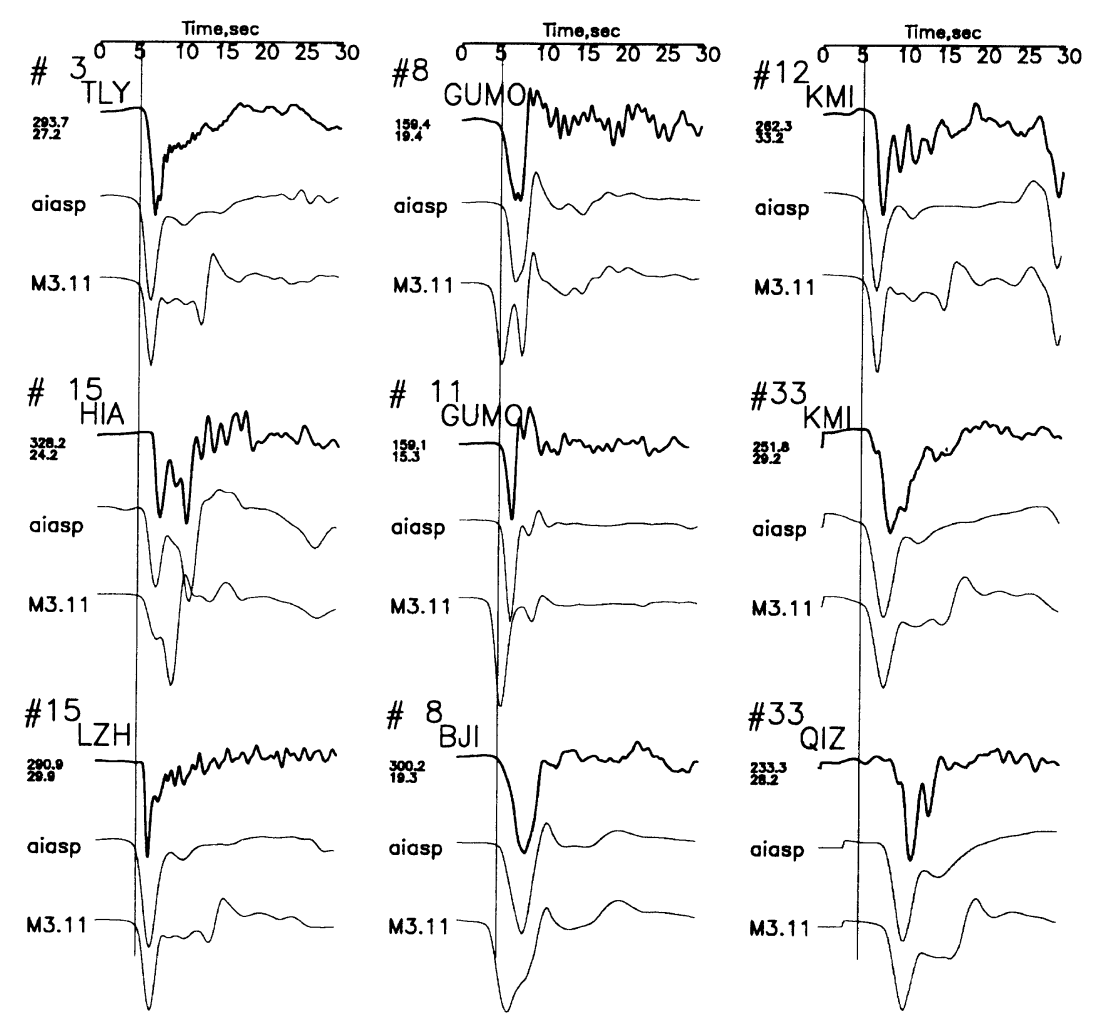

(b)

Fig. 5. (continued).

most Philippine Sea, suggesting that the depression of the $660 \mathrm{~km}$ discontinuity may not be continuous along the IzuBonin arc to its southern end but terminate near the southern end of the fast anomaly zone imaged by the tomographic model beneath the northernmost Philippine Sea. The results are also in good agreement with those by van der Hilst et al. (1991) and van der Hilst and Seno (1993).

The waveform analysis carried out by Tajima and Grand (1998) is relatively simple and therefore limited to modeling the complex velocity structure in the upper mantle. Nonetheless this approach is efficient to identify velocity anomalies associated with flattened slab at the bottom of the upper mantle because the relative time interval between the first and secondary arrivals can be effectively modeled for the depth range where the rays bottom and turn upward. With a comparison of the tomographic images and the waveform modeling we suggest the followings: a certain degree of flattened slab exists at the bottom of the upper mantle associated with subduction zones in the northwestern Pacific but the volume of stagnant slab is smaller than the impression given by the ISC tomographic models; the transition zone in the southern Kurile to northeastern Japanese subduction zones has a southwestern boundary which distinguishes the structure from the surrounding regions; there is a gap of transition zone anomaly in the region beneath the Yellow Sea to East China Sea; and the high velocity anomaly in the transition zone is not accompanied by a broad depression of the "660" km discontinuity beneath the northernmost Philippine
Sea plate, the back arc of the Izu-Bonin subduction zone.

\section{Tomographic Image and Seismic Rays}

The regional $P$ wave analysis (Tajima and Grand, 1998) as described above found some similar features of high velocity anomalies to those determined in the depth range between 551 and $712 \mathrm{~km}$ by the ISC tomographic model (Obayashi et al., 1997) (compare the tomographic images in Fig. 2(a) with the regionalization in Fig. 4). The transition zone structure in that depth range was strongly sampled only by secondary arrivals of triplicated $\mathrm{P}$ waves which are not included in the ISC catalog (Tajima and Grand, 1995, 1998). The high velocity anomalies in the transition zone in regions $a$ and $b$ are also accompanied by a depression of the discontinuity at $\sim 660 \mathrm{~km}$, for which the tomographic inversion does not have resolution. Most of large-scale tomographic studies such as the one by Obayashi et al. (1997) do not calculate wave propagation through the derived 3-D structure. The problem with using 1-D model ray tracing and reflectivity synthetic calculations is that there may be a substantial difference between the actual and assumed ray path locations. Knowing these limitations, the similarity of the high velocity zone distribution determined by the two different approaches is interesting. Here the tomographic images are examined along several sets of seismic rays for which the $\mathrm{P}$ wave velocity structure is delineated either by M3.11 or iasp91.

Figure 6 shows cross projection profiles superposed by the first and second arriving rays for the triplicated $\mathrm{P}$ wave 

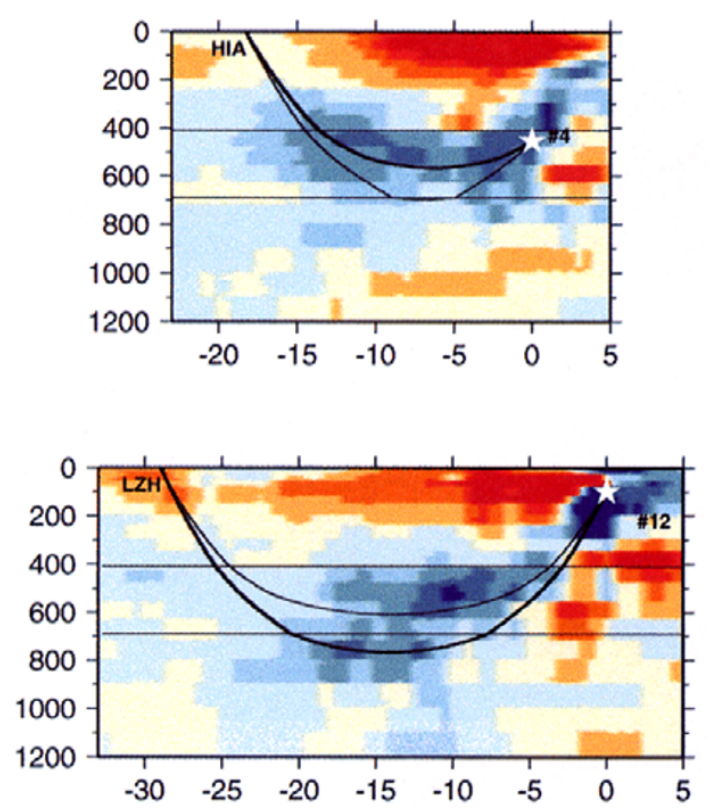
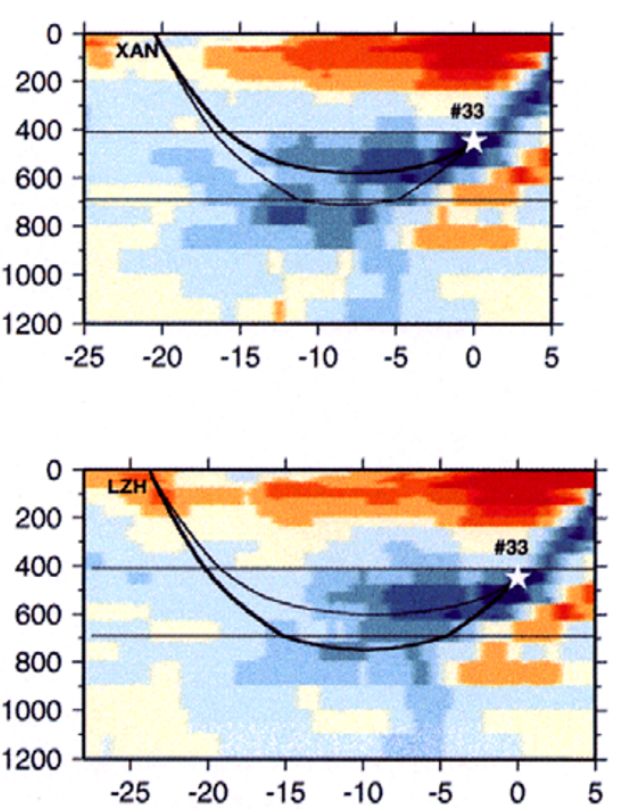

Fig. 6. Cross projection profiles of slowness along some of the ray paths (see the event and station locations on the map view in Fig. 4) for the preferred model of M3.11. Compare the image with results of the waveform modeling in Fig. 5(a). Although the peak of high velocity anomalies is in the depth range $478-551 \mathrm{~km}$ in the tomographic model, the agreement between the tomographic image and the waveform modeling is very reasonable along these profiles.
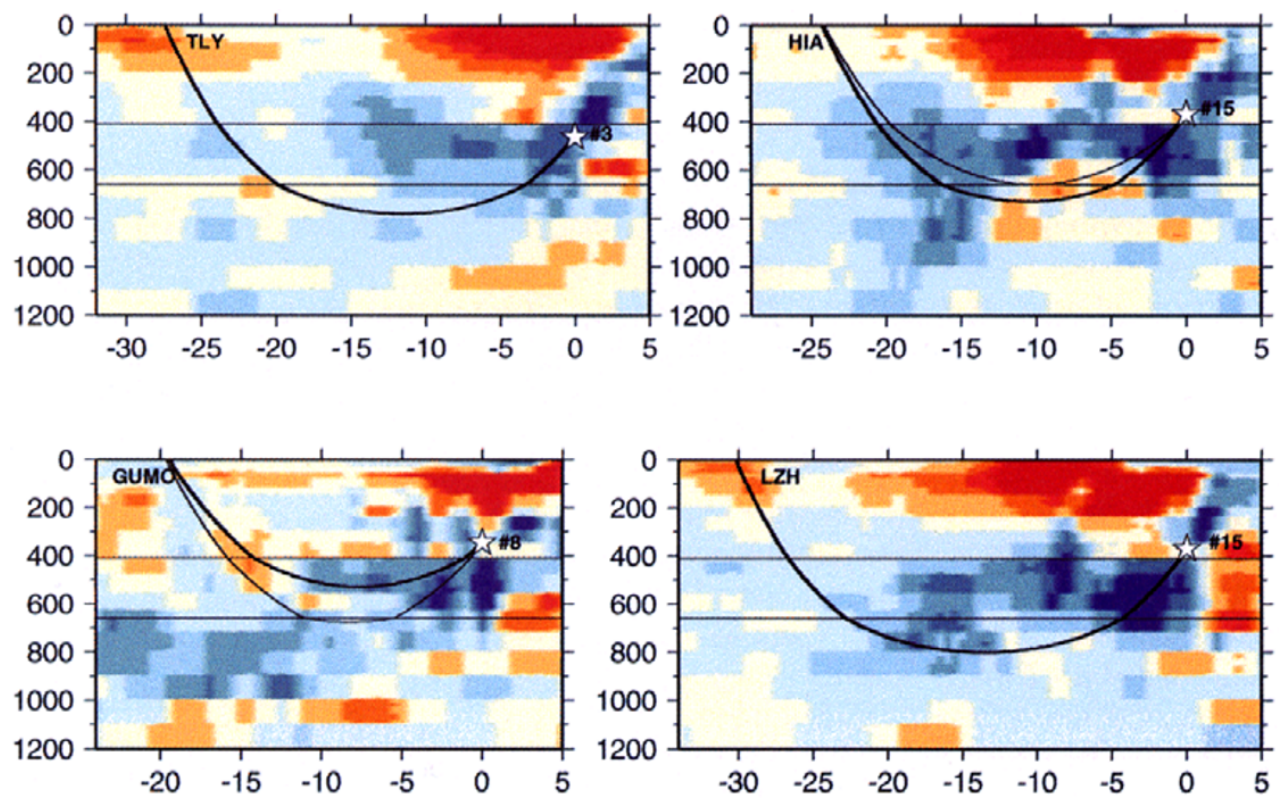

Fig. 7. Same as Fig. 6 for the preferred model iasp91.

observed at HIA for event \#4, those of event \#33 at XAN and LZH, and that of event \#12 at LZH (see the horizontal view of the rays in Fig. 4). These $P$ waves are modeled by M3.11 well (see Fig. 5(a)). The bold lines show first arriving rays and the thin lines second arrivals which are turning either above or below the discontinuity at $690 \mathrm{~km}$. Note that the sampling depths and distance range where triplication is observed depend on the velocity structure. The waveform of event \#4 at HIA, in particular, the separation of the first and second arrivals was modeled well by M3.11. The first arriving ray bottomed at $\sim 550 \mathrm{~km}$ and strongly sampled the transition zone where the tomographic image also indicates high velocity anomaly. The second arrival turned below the discontinuity where the tomographic image does not show significant anomaly. The first arriving rays at LZH from event \#12 and event \#33 both bottomed below the transition zone and the second arrivals in the transition zone. The tomographic image where the second arriving rays turn shows 
a flattened high velocity anomaly. The first arriving ray of event \#33 at XAN bottomed in the transition zone and second arriving rays below the discontinuity. The focus of the flattened high velocity anomalies is, however, shallower than $\sim 550 \mathrm{~km}$ unlike the implication by the waveform modeling.

Figure 7 shows cross projection profiles superposed by the seismic rays for the waveforms of event \#3 observed at TLY, event $\# 15$ at HIA and LZH, and event \#8 at GUMO. All these $\mathrm{P}$ waves were modeled well by iasp91 although the ray paths lie within the region where the tomographic model gives an impression of a large-scale stagnant slab. The tomographic image indicates that the transition zone along the ray paths of event \#3 to TLY and event \#15 to LZH includes a flattened high velocity anomaly in the transition zone. If there were such a broad high velocity anomaly accompanied by a depression of the $660 \mathrm{~km}$ discontinuity, secondary arrivals should have been observed at these stations (see the synthetics with M3.11 in Fig. 5). However, the observed P waves do not show triplication, which is more favorable for a standard velocity model. With a closer look the event \#15 P wave observed at HIA bottomed in the area where the tomographic image shows slightly low velocity anomaly beneath a flattened high velocity zone at shallower transition depths.

The first arriving P observed at GUMO for event \#8 appears to turn in a flattened high velocity zone extending from strong high velocity anomaly beneath the hypocenter while the later arriving $P$ turns in the less anomalous deeper mantle. The waveform at GUMO was modeled with iasp 91 well, suggesting that the flattened high velocity zone does not extend southward to such an extent as indicated in the tomographic image or the effect of high velocity anomaly has been canceled by the presence of a low-velocity zone ahead of the flattened high velocity zone (see the ray path in Fig. 7).

The waveform modeling indicates variation of the transition zone anomalies (regions a, b, c and d in Fig. 4). The less anomalous region c lies beneath East China Sea that separates the anomalous region $\mathrm{b}$ on the continental side from the other anomalous region $d$ on the Philippine Sea side. In the tomographic images this feature is most clearly seen in the depth range 629-712 km (Fig. 2(a)). The ray from event \#15 to LZH bottoms in this range (Fig. 7) and the waveform prefers iasp91. Similarly, in two depth ranges 551-629 km and 629-712 km (Fig. 2(a)) region a and region d are separated by a low velocity zone beneath Japan Sea. The first and later arriving rays from event \#15 to HIA bottoms in these depth ranges (Fig. 7) and the waveform also prefers iasp 91.

The resolving kernels shown in Fig. 8 indicates that the tomographic images around the turning rays in these boundary regions are well resolved. Here the size of each block evaluated is the same as in Model G1 and the shades represent four ranges of the orthogonal component values, i.e., over 0.9 (black), between 0.9 and 0.8 (slightly lighter), between 0.8 and 0.6 (lighter), less than 0.6 (lightest). The resolving kernels show high values (over 0.8) for the areas along the bottoming P rays. Another interesting feature associated with the slab-like high velocity anomalies is that they are accompanied by a downward extension beyond the flattened zone, notably along the \#12 ray to LZH and \#33 ray to XAN (Fig. 6) and along the \#15 rays to HIA and LZH (Fig. 7). Assuming a good resolution around the depth range in these
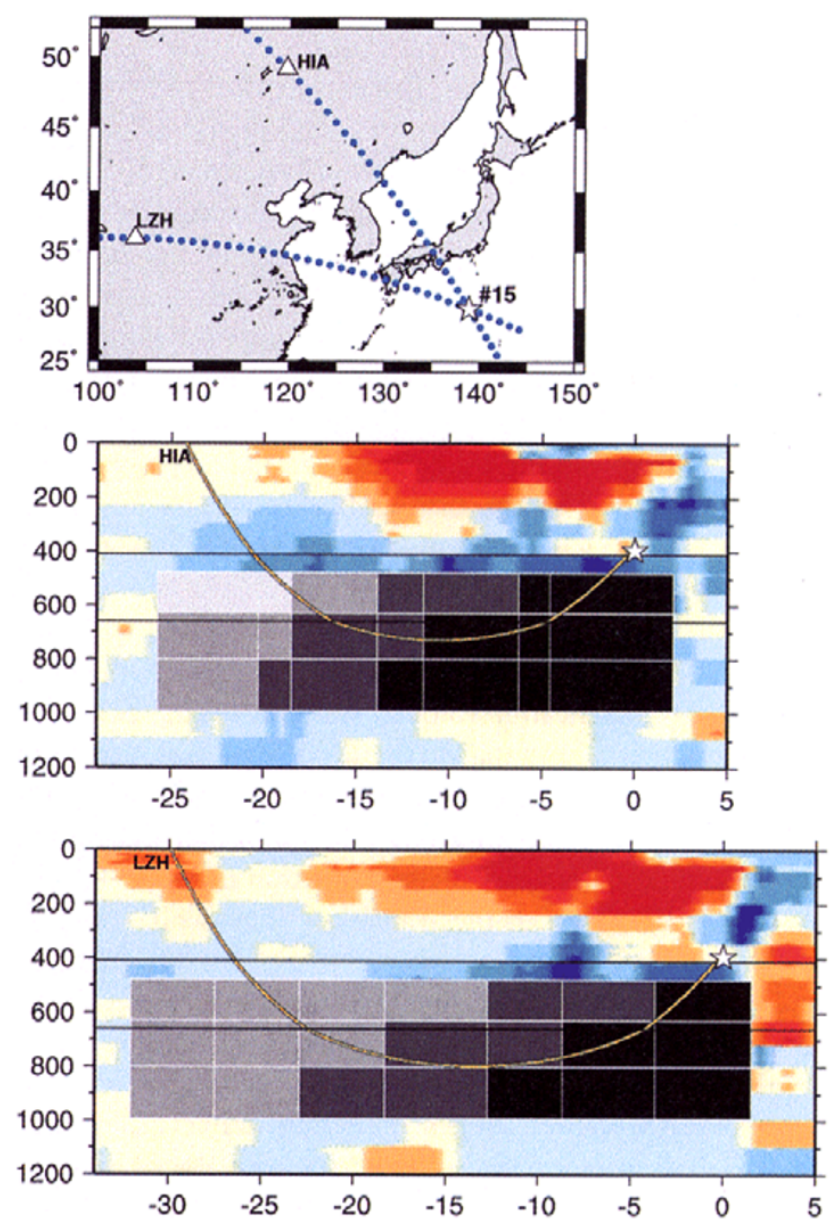

Fig. 8. Resolving kernels along the profiles (middle) between Event \#15 and station HIA and (bottom) between Event \#15 and LZH for blocks $\left(5.625^{\circ} \times 5.625^{\circ}\right)$. The rays are shown on the map (top). The shade in each block indicates the orthogonal component value ranging over 0.9 (black), between 0.9 and 0.8 (slightly lighter), between 0.8 and 0.6 (lighter), less than 0.6 (lightest). The ray from event 15 to HIA passes through two fast regions a and d but bottoms in the low-velocity zone under the Japan Sea and its waveform prefers iasp91. The ray from the same event to LZH leaves the fast region d near the source but bottoms in a much less anomalous zone under the East China Sea and its waveform again prefers iasp 91 .

regions, this may indicate continuing subduction below the transition zone.

\section{Discussion and Summary}

The large-scale subhorizontal image of high velocity anomalies in the tomographic model of Obayashi et al. (1997) (i.e., Model G3) was evaluated using results of the regional waveform analysis by Tajima and Grand (1998). The regional variation of anomalous structure identified by the waveform modeling can be recognized in the tomographic image in which the anomalous structure in the north (region a in Fig. 4) is distinguished from those to the southwest (i.e., regions $b$, c, and d) showing a shorter wavelength of variation of anomalies. There seems to be a discrepancy of transition zone velocity anomalies between the tomographic model and the waveform modeling, as well. The tomographic model determines the largest lateral extent of high velocity anomalies 
in the depth range 478-551 km (Fig. 2) although the resolution test does not provide strong support for the features in this depth range (see Fig. A1). The waveform modeling of Tajima and Grand (1998) does not find evidence of strong high velocity anomalies at depths shallower than $525 \mathrm{~km}$.

The anomalous model M3.11 has the strongest high velocity anomaly in a depth range $525-575 \mathrm{~km}$, below which the anomaly decreases with increasing depth and vanishes at $660 \mathrm{~km}$. The global waveform inversion for the $\mathrm{S}$ wave speed by Li and Romanowicz (1996) shows the strongest fast anomaly in a depth range $500-550 \mathrm{~km}$ in the northwestern $\mathrm{Pa}-$ cific (Fig. 2(b)). Taking into account of the advantages and limited resolutions of the three different approaches, these results lead us to a suggestion that the velocity structure associated with a flattened slab has the strongest anomaly not immediately above the $660 \mathrm{~km}$ discontinuity but at depths $\sim 100 \mathrm{~km}$ shallower than $660 \mathrm{~km}$. The waveform modeling also suggests that the high velocity anomaly disappears above $\sim 525 \mathrm{~km}$ more rapidly than at depths deeper than $\sim 525 \mathrm{~km}$.

The above feature appears to be consistent with the thermochemical model of down-going slab in which the normal olivine mantle undergoes phase transition $\alpha \rightarrow \alpha+\beta \rightarrow$ $\beta \rightarrow \beta+\gamma \rightarrow \gamma$ in the transition zone while the cold slab experiences $\alpha \rightarrow \alpha+\gamma \rightarrow \beta+\gamma \rightarrow \gamma$ where the $\beta+\gamma$ field is very small (Bina, 1996). In this model a large velocity contrast exists between the cold slab in the $\gamma$ field and the surrounding mantle in the $\beta$ or $\beta+\gamma$ field (Okal and Kirby, 1998). If such a cold slab deflects above the $660 \mathrm{~km}$ discontinuity, we expect a larger velocity contrast near the top, rather than near the bottom, of the deflected slab, resulting in a velocity profile similar to M3.11 (Fig. 3).

The boundaries of anomalous structures identified by the waveform modeling can be also recognized in the tomographic image. The anomalous structure in the north (region a) has a distinct southwestern boundary beyond which the transition zone structure shows a shorter wavelength of variation. The tectonic history suggests different ages of subducted slabs from segment to segment there. It is suggested that the Bohai Sea Basin (region b) evolved most actively with the subsidence and magmatism from Eocene to Oligocene $(\sim 35 \mathrm{Ma})$. The formation in region $\mathrm{c}$ is relatively new. In the western part of the Okinawa trough rifting and spreading started around the middle of Miocene. Variation of slab morphology in the northwestern Pacific is also suggested by several others. Ohtaki and Kaneshima (1994) used differential travel time residuals to isolate near source contributions and suggested that the slab around the northern Izu-Bonin arc is flattened above the $660 \mathrm{~km}$ discontinuity and then connected by a zone with a steep dip angle to the south. A similar feature is seen in the tomographic model along the ray of event \#8 to GUMO (see also van der Hilst et al. (1991) and van der Hilst and Seno (1993)).

The resolution of the tomographic inversion for the deeper part of the transition zone depends on the proximity of stations or earthquake sources because only crossing $\mathrm{P}$ waves that sample the depth range can be recorded as first arrivals in the ISC catalog. While first arriving $\mathrm{P}$ waves in the ISC catalog poorly sample upper mantle in general, the transition zone near high seismic activity and a dense station distribution seems to be fairly well sampled by crossing seismic waves. The improved image in Model G3 is mainly due to the increased coverage of crossing rays. The overall features associated with the subducted slabs at the bottom of the transition zone are found similar to each other between the two different approaches. This result also leads to an indication that the volume of stagnant slab in the transition zone may be smaller than the first impression suggested by the ISC tomographic model of Fukao et al. (1992). Some high velocity zones in the tomographic image are continuous to lower mantle from the flattened part in the transition zone (see Figs. 6 and 7). This observation along with the large volumes of high velocity anomalies in mid-mantle (at depths of over $900 \mathrm{~km}$ ) beneath Kalimantan (formerly Borneo) and Sea of Okhotsk is favorable for the argument that a stagnant slab eventually descends into lower mantle (Fukao et al., 1992). If so, there are outstanding questions as to what controls the slab behavior for stagnation, how much of the subducted slab can stagnate in the transition zone before it eventually sinks, and to what depths the slabs sink as distinct units? These issues are also addressed by Zhou et al. (1990), Grand (1994), Kawakatsu and Niu (1994), and van der Hilst et al. (1997).

Acknowledgments. We thank S. P. Grand for valuable suggestions and comments during the course of this study, and B. Romanowicz for making Model SAW12D of Li and Romanowicz available to us for this study. We also thank F. Niu for assisting in graphic display at an early stage, H. Kawakatsu, C. Bina, and T. Hara for helpful discussion. Review comments by R. van der Hilst helped improve the clarity of the manuscript. Figures 1, 2, 4, 6, 7, 8, and A1 were drawn using the GMT software developed by P. Wessel and W. H. Smith. This study was partially supported by National Science Foundation grants no. EAR-9526678, no. INT-9603327, and no. EAR-9805006, and a visiting professorship at the University of Tokyo (F.T.), and a grant in aid from Japan Society of Promotion of Science (Y.F.).

\section{Appendix. Resolution of Model G3}

A checker board test is an effective measure to evaluate the resolution of inversion. Figure A1 demonstrates the recovery of a checker board test. Here the input checker board pattern was given in blocks of the same discretization as in Model G1, i.e., $5.625^{\circ} \times 5.625^{\circ}$ in latitude and longitude and varying layer thicknesses with depth (Inoue et al., 1990) but the recovery test was performed using the same discretization and event-station pairs as in Model G3 (Obayashi et al., 1997). In general the recovery of the input model is poor for upper mantle structure except near the subduction zones. Another recovery test was performed for an input checker board pattern in blocks as were used in Model G3 but the block size given around the subduction zones in this case was too small to recover the alternating positive and negative anomalies. Nonetheless the test result shown in Fig. A1 as well as the resolving kernels for Model G3 (Fig. 8) indicate a good resolution for a continuous feature associated with the subduction zones using the present data set. As is described in the text, Model G3 produced a sharper image for the structure associated with subducted slabs in the deeper part of the transition zone ( $\gtrsim 551 \mathrm{~km}$ ) presumably owing to the increase of $\mathrm{P}$ travel time data. The depth range can be sampled only by crossing $\mathrm{P}$ waves which propagate to stations as first arrivals. 

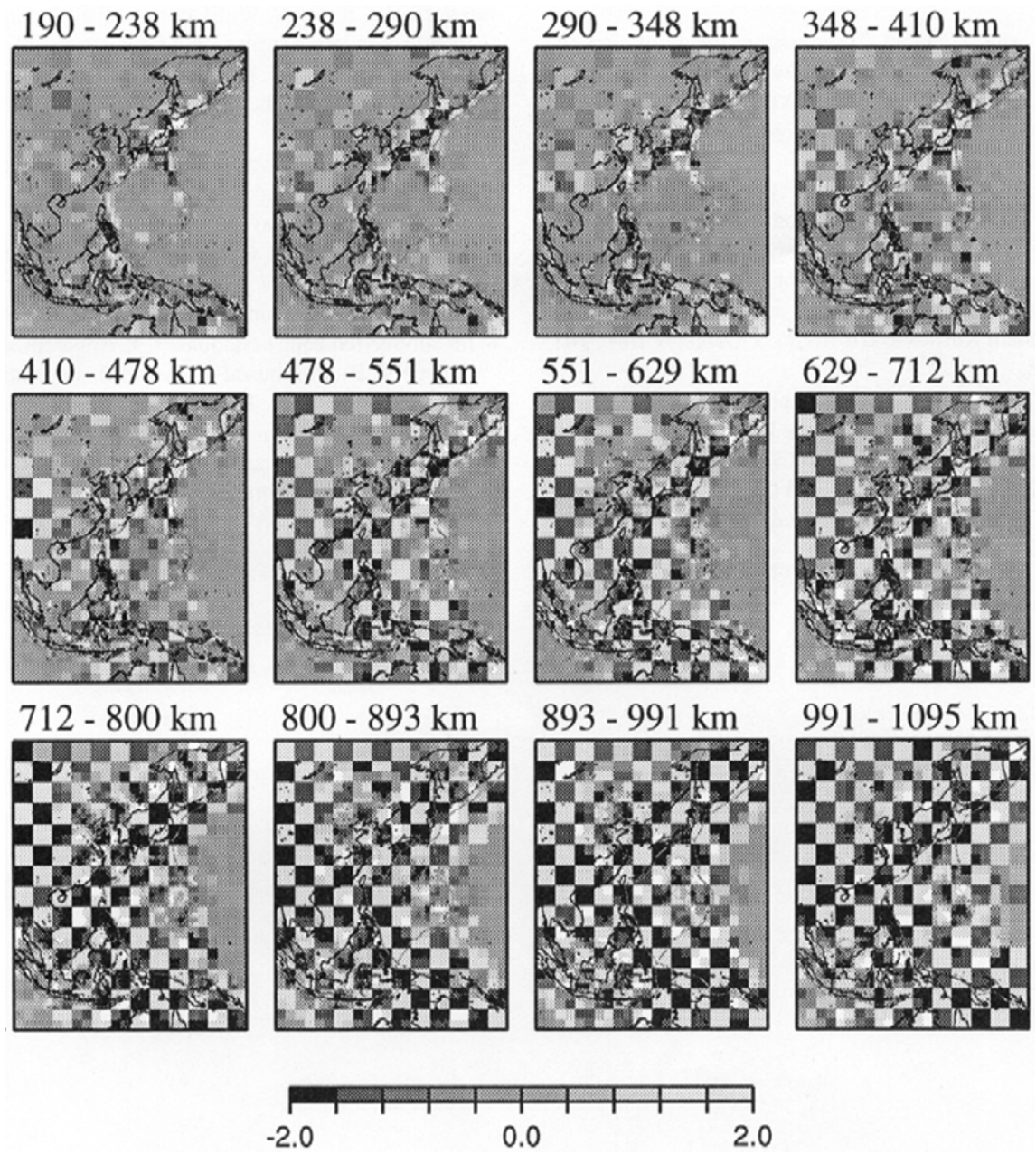

Fig. A1. Checker board test results using the same event-station pairs and blocks with the lateral discretization of $5.625^{\circ} \times 5.625^{\circ}$. Generally the resolution in the upper mantle (e.g., shallower than $712 \mathrm{~km}$ ) is poor except in the areas where the station coverage is good and/or the seismicity is high such as around the Japan Islands and the eastern Eurasian continent. Sampling in the poorly resolved areas are mostly by crossing rays at a steep angle, which are not very sensitive to the structure in that depth range.

\section{References}

Bina, C. R., Phase transition buoyancy contributions to stresses in subducting lithosphere, Geophys. Res. Lett., 23, 3563-3566, 1996.

Brudzinski, M. R., W.-P. Chen, R. L. Nowack, and B.-S. Huang, Variations of P-Wavespeeds in the mantle transition zone beneath the northern Philippine sea with implications on mantle, dynamics, J. Geophys. Res., 102, 11,815-11,827, 1997.

Bullen, K. E., An Introduction to the Theory of Seismology, 3rd edition, Cambridge Univ. Press, 1963.

Castle, J. C. and K. Creager, Seismic evidence against a mantle chemical discontinuity near $660 \mathrm{~km}$ discontinuity beneath Izu-Bonin, Geophys. Res. Lett., 24, 241-244, 1997.

Collier, J. D. and G. R. Helffrich, Topography of the " 410 " and " 660 " discontinuities in the Izu-Bonin subduction zone, Geophys. Res. Lett., 24, 1535-1538, 1997.

Creager, K. C. and T. H. Jordan, Slab penetration into the lower mantle, $J$. Geophys. Res., 89, 3031-3049, 1984.

Creager, K. C. and T. H. Jordan, Slab penetration into the lower mantle beneath the Mariana and other island arcs of the northwest Pacific, $J$. Geophys. Res., 91, 3573-3589, 1986.

Fukao, Y., Upper mantle P structure on the ocean side of the Japan-Kurile arc, Geophys. J. R. Astron. Soc., 50, 621-642, 1977.

Fukao, Y., M. Obayashi, H. Inoue, and M. Nenbai, Subducting slabs stagnant in the mantle transition zone, J. Geophys. Res., 97, 4809-4822, 1992.

Grand, S. P., Mantle shear structure beneath the Americas and surrounding oceans, J. Geophys. Res., 99, 11591-11621, 1994.

Herrin, E., W. Tucher, J. Taggart, D. W. Gordon, and J. L. Lobdell, Es- timation of surface focus P travel times, Bull. Seismol. Soc. Am., 58 1273-1291, 1968

Inoue, H., Y. Fukao, K. Tanabe, and Y. Ogata, Whole mantle P-wave travel time tomography, Phys. Earth Planet. Inter., 59, 294-328, 1990.

Kamiya, S., T. Miyatake, and K. Hirahara, How deep can we see the high velocity anomalies beneath the Japan islands?, Geophys. Res. Lett., 15, 828-831, 1988

Kamiya, S., T. Miyatake, and K. Hirahara, Three-dimensional P-wave velocity structure beneath the Japanese islands, Bull. Earthquake Res. Inst. Univ. Tokyo, 64, 457-485, 1989

Kawakatsu, H. and F. Niu, Seismic evidence for a $920-\mathrm{km}$ discontinuity in the mantle, Nature, 371, 301-305, 1994.

Kennett, B. L. N. and E. R. Engdahl, Traveltimes for global earthquake location and phase identification, Geophys. J. Int., 105, 429-465, 1991.

Li, X. and B. Romanowicz, Global mantle shear velocity model developed using nonlinear asymptotic coupling theory, J. Geophys. Res., 101, 22245-22272, 1996.

Obayashi, M., T. Sakurai, and Y. Fukao, Comparison of recent tomographic models, Abstract of International Symposium on New Images of the Earth's Interior through Long-term Ocean-floor Observations, 29, 1997.

Ohtaki, T. and S. Kaneshima, Continuous high velocity aseismic zone beneath the Izu-Bonin arc, Geophys. Res. Lett., 21, 1-4, 1994.

Okal, E. A. and S. H. Kirby, Deep earthquakes beneath the Fiji basin, SW Pacific: Earth's most intense deep seismicity in stagnant slabs, Phys. Earth Planet. Inter., 1998 (in press).

Ringwood, A. E. and T. Irifune, Nature of the $650 \mathrm{~km}$ seismic discontinuity: Implications for mantle dynamics and differentiation, Nature, 331, 131- 
136,1988

Sakurai, T., M. Obayashi, and Y. Fukao, Tomographic image of slab and mantle plume, Program and Abstracts, Seism. Soc. Japan, 1, 189, 1995.

$\mathrm{Su}$, W. J., R. L. Woodward, and A. M. Dziewonski, Degree 12 models of shear velocity heterogeneity in the mantle, J. Geophys. Res., 99, 3694536980, 1994.

Tajima, F. and S. P. Grand, Evidence of high velocity anomalies in the transition zone associated with southern Kurile subduction zone, Geophys. Res. Lett., 22, 3139-3142, 1995.

Tajima, F. and S. P. Grand, Variation of transition zone high velocity anomalies and depression of the $660 \mathrm{~km}$ discontinuity associated with subduction zones from the southern Kuriles to Izu-Bonin, J. Geophys. Res., 103, B7, 15015-15036, 1998 .

van der Hilst, R. D. and T. Seno, Effects of relative plate motion on the deep structure and penetration depth of slabs below the Izu-Bonin and Mariana island arcs, Earth Planet. Sci. Lett., 120, 395-407, 1993.

van der Hilst, R. D., R. Engdahl, W. Spakman, and G. Nolet, Tomographic imaging of subducted lithosphere below northwest Pacific islands arcs, Nature, 353, 37-43, 1991. van der Hilst, R. D., S. Widiyantro, and E. R. Engdahl, Evidence for deep mantle circulation from global tomography, Nature, 386, 578-589, 1997.

Wicks, C. W. and M. A. Richards, A detailed map of the 660-kilometer discontinuity beneath the Izu-Bonin subduction zone, Science, 261, 1424 1426, 1993.

Widiyantoro, S. and R. van der Hilst, Structure and evolution of lithospheric slab beneath the Sunda arc, Indonesia, Science, 271, 1566-1570, 1996.

Zhou, H. and R. W. Clayton, $\mathrm{P}$ and $\mathrm{S}$ travel time inversions for subducting slab under the island arcs of the Northwest Pacific, J. Geophys. Res., 95, 6829-6851, 1990

Zhou, H., D. L. Anderson, and R. W. Clayton, Modeling of residual spheres for subduction zone earthquakes, 1, Apparent slab penetration signatures in the NW Pacific caused by deep diffuse mantle anomalies, J. Geophys. Res., 95, 6799-6827, 1990.

F. Tajima (e-mail: fumiko@physics.utexas.edu), Y. Fukao, M. Obayashi, and T. Sakura 